\title{
The management of pain due to cervical multilevel disc bulges and spinal stenosis with a novel wave treatment: A case report.
}

\author{
Arwa Abuomar ${ }^{1}$, Mohammed Albaradie $^{1}$, Hussain Aldera ${ }^{2}$, Christopher Vannabouathong ${ }^{3}$, \\ and Lee Bartel ${ }^{4}$ \\ ${ }^{1}$ KKT Orthopedic Spine Center \\ ${ }^{2}$ King Saud bin Abdulaziz University for Health Sciences College of Medicine \\ ${ }^{3}$ Neuro Spinal Innovations \\ ${ }^{4}$ University of Toronto
}

September 24, 2021

\begin{abstract}
A patient presenting with low back pain received 18 novel treatments of FDA approved low frequency sound wave stimulation known as Khan Kinetic Treatment (KKT). Following KKT he demonstrated improvement in pain, function, quality of life, sleep, and trunk range of motion with no adverse events.
\end{abstract}

\section{Introduction}

Back pain is the leading cause of disability worldwide, with up to $80 \%$ of the population experiencing back pain at some point in their life. ${ }^{1,2}$ The cost of back pain in the United States of America (USA) alone is estimated to exceed $\$ 50$ billion per year. ${ }^{3}$ Chronic back pain is complex, and various treatment options, ranging from conservative therapies to invasive surgery, exist for the management of these patients. ${ }^{4-7}$ The Khan Kinetic Treatment (KKT) approach aims to provide orthopaedic spinal treatment through focused vibroacoustic treatment (fVAT) and manage the biomechanical aspect of back pain. Vibroacoustic therapy has been indicated for patients with a range of musculoskeletal, neurological, and haemodynamic problems demonstrating positive changes in pain, spasticity, movement control, and specifically fatigue and anxiety in those with spinal cord or brain injuries. ${ }^{8-13}$ The musculoskeletal effects specifically include stimulation of mRNA expression of proteins key to spinal health and a positive cellular environment for ligament repair. ${ }^{12}$ KKT involves the application of sine waves, within the audible spectrum, directed towards the spine. The low-frequency sound waves produce mechanical vibrations that cause delicate reverberations of the vertebrae, and minor repetitive stretching and activation of the attached soft tissues at multiple spine levels. ${ }^{14-16}$

Treatments for chronic back pain should relieve pain, improve spinal misalignment, and help heal ligamentous structures, and KKT addresses all of these factors by: 1) stimulating biosynthesis of intervertebral disks, 2) correcting abnormal mean axis of rotation of intervertebral joints, 3) activating spinal cord circuitry that "gates" pain transmission and reducing gamma motor neuron activity, 4) relaxing paraspinal muscles, ensuring asymmetrical loads on the spine are minimized, and 5) increasing muscle coordination, due to the decreased pain, which plays a critical role in spine stabilization. ${ }^{14,15}$ Clinical evidence from published reports demonstrated that KKT relieves back and neck pain, corrects spinal alignment, and enhances the genetic expression of important proteins in the discs. ${ }^{14,15,17,18}$ The following is a case report of a young patient who presented with both low back pain and neck pain, treated with KKT.

\section{Case presentation}




\section{Patient description \& history}

A 23 year old male healthcare worker presented with low back pain radiating to his right lower limb and neck pain radiating to both shoulders. His symptoms started three years prior to presentation, which were aggravated by standing, sitting, walking, neck flexion, neck extension, and weightlifting. Upon presentation, he stated that the "pain is as bad as it could be". He has had diabetes type I since childhood, taking insulin regularly. He had no history of osteoporosis or malignancy. Pain medications and conservative therapies did not improve his pain or sleep. Prior therapies included pregabalin, meloxicam, and celecoxib, and he complained of worsening symptoms following physical therapy and massage therapy. The patient provided his informed consent to publish the results of his treatment.

Physical examination $\&$ diagnosis

On physical examination, the patient had severe tenderness over the lumbosacral and midthoracic spine, moderate limitation in trunk flexion and extension due to pain, decreased left side patellar reflex, and a positive straight leg raise (SLR) test on his right side.

The clinician conducted a series of physiological tests before each treatment: (1) cervical range of motion (ROM); (2) the shoulder and pelvic tilt angle determined to the quarter degree in the coronal plane with a set of callipers; (3) arm and leg coordinated response to resistance; (4) supine leg length discrepancy; and (5) deep spinal palpation for the assessment of tender lesions. Depending on pre-treatment results, these tests were repeated immediately after each treatment application. On the initial examination the patient had normal cervical ROM to the right and mild restriction to the left; the shoulder angle deviated to the left by one degree and the hip angle deviated to the left by 1.25 degrees; arm coordinated response to resistance was reduced on the left $(3 / 5)$ and on the right $(4 / 5)$ while legs were $3 / 5$ bilaterally; leg length on the left side was $1 \mathrm{~cm}$ shorter compared to the right; and the clinician found 13 tender lesions with considerable pain at various points along the spine.

The patient had magnetic resonance imaging (MRI) of the cervical spine and was diagnosed with cervical multilevel disc bulges with mild to moderate spinal canal stenosis (Figure 1 ). Other possible diagnoses considered were multilevel cervical spondylosis, cervical intervertebral disc degenerative disease with myelopathy, and muscle spasm. The patient had a Visual Analogue Scale (VAS) for pain score of 9.85/10, Neck Disability Index (NDI) score of 29/50 (58\%), and Roland-Morris (RM) score of 8 points.

\section{Treatment plan $\&$ follow-up}

The KKT treatment device consists of a controller mounted on top of an impulse delivery mechanism, or device head, which in turn is mounted on a movable armature to a fixed stand. ${ }^{14,15}$ The device head may be moved freely in three dimensions. At the base of the device head, there is a stylus used to deliver the sinusoidal wave forms of various frequencies and intensities (Figure 2 ). The device can be applied anywhere along the entire spine and related points at the discretion of the treating physician. Initial treatment parameters are created on basis of digital data captured through X-rays of the spine. The treatment plan for the patient was for 12 sessions of KKT on alternate days followed by six once weekly follow-up sessions along with physician-recommended lifestyle modifications. Table 1indicates the anatomical locations at which treatment was administered and the number of pulses used during each treatment session. The patient was largely compliant with the 12 treatment schedule, but the first follow-up treatment was delayed by almost two months.

The patient completed the VAS for pain after every six sessions, while the NDI and RM questionnaire were recorded at the initial session and after the final follow-up session.

\section{Outcomes}

Following the first KKT treatment, the patient's experienced immediate normalization of his left patellar reflex, trunk flexion, and trunk extension. He also experienced improvement of pain outcomes. From the 13 painful tender lesions at intake, these were reduced to 5 by treatment 7 and to 0 by treatment 12 . The 
patient's VAS pain score reduced from 9.85 at intake to 3.51 by the final treatment session and 4.48 by the final follow-up session. His NDI score reduced to $11 / 50(22 \%)$ by the final follow-up session, and his RM score reduced to 6 points. The patient stated that there was a noticeable improvement in his quality of life and sleep, and that he could now perform better at work due to his improvement in physical activity and reduced pain. It is noteworthy that the patient had a few relapses because of excessive workloads and did not always adhere to his doctor's recommendations.

Along with improved symptoms, there was also a notable correction in the biomechanics of his spine and body. Shoulder and pelvic tilts steadily improved with KKT treatment, until it became neutral from the $5^{\text {th }}$ treatment onwards. After the $7^{\text {th }}$ treatment, the patient had full cervical ROM. After completing his treatment sessions, MRI imaging showed resolution of cervical disc bulging. After reviewing all the MRI slices, the orthopaedic surgeon noticed improvement in disc hydration in all cervical spine discs, a reduction in spine cord compression at levels C4-C5 and C5-C6, and no stenosis in in the cervical spine (Figure 3 ). The patient did not experience any adverse events related to the treatment.

\section{Discussion}

The management of chronic back pain is complex and continues to be a leading cause of disability and productivity loss worldwide. ${ }^{1,2,5}$ Treatment can include a combination of various medical, psychological, and physical therapies. After these conservative options fail, more invasive and irreversible surgical intervention may then be offered to certain patients as a last resort, for those who qualify. ${ }^{4-7}$ However, spine surgery does not guarantee long-term symptomatic relief, patient satisfaction, or return to daily living and is associated with complications, highlighting the need for less invasive treatment options. ${ }^{19-21}$

The KKT approach can fulfill this unmet need by treating patients by means of precisely directed sound stimulation. The current case study of a young patient who presented with both low back and neck pain treated with KKT is consistent with the previously published evidence. ${ }^{14,15,17,18}$ After completion of his sixth maintenance session, the patient exhibited improvements in pain and disability scores, trunk range of motion, quality of life, sleep and work performance with no reports of adverse effects. Documented improvement in cervical spine stenosis was noted on MRI.

The use of focused low frequency sound waves in the treatment of spinal pathologies is a novel medical development which has been largely spearheaded by the KKT clinical and scientific teams. This particular case is notable as, in addition to improvement in symptoms and quality of life, remarkable changes were also seen on MRI following KKT in a short time period. This case demonstrates the substantial physiological effect rhythmically pulsed spinal stimulation therapies including sound waves can play in the nonsurgical management of patients with spinal pathologies. Although repetitively pulsed electrical stimulation has demonstrated some promising results in the literature in patients with lumbar spinal stenosis, ${ }^{22,23}$ less has been reported with sound wave stimulation. A greater understanding of the physiological changes that happen to the spine and its surrounding structures during sound wave treatment is needed. The current RCT evidence on KKT has demonstrated significantly improved pain and functional outcomes compared to controls in patients with chronic neck or low back pain. ${ }^{14,15,18}$ More specially, one of the earliest studies looking at the clinical effects of this device showed that a significant number of patients with chronic back and neck pain experienced significant improvement in pain scores and a decrease in pain medication requirements.

${ }^{18}$ Follow up studies showed that the waves induced beneficial mechanical changes in the vertebrae, restoring the vertebral column to a more natural alignment. ${ }^{14}$ Subsequent studies investigated possible cellular changes induced by the waves. Animal studies on bovine intervertebral discs showed that waves from the KKT device induced upregulation of matrix protein mRNA, such as aggrecan and collagen type II. ${ }^{17}$ All of these proteins are associated with disc hydration and disc health. Continued large-scale studies on the use of KKT for this indication will assist in validating these findings.

\section{Conclusion}

The KKT approach demonstrates promising results, with limited safety concerns, in a young patient diagnosed with cervical multilevel disc bulges with mild to moderate spinal canal stenosis. The patient ex- 
perienced symptomatic relief and, as a result, improved quality of life and work performance. Positive structural changes were also seen on MRI. His improvement is consistent with multiple randomized control trials showing benefits of the KKT treatment.

\section{Acknowledgements}

Dr. Aslam Khan for advice in selecting the case and comments on the draft of the manuscript. Dr. Peter Dyback for explanatory comments on an early draft of the manuscript. Dr. Karim Bayanzay for comments on a draft of the manuscript. Amani AlAmri and Nora AlWahbi for assistance with the treatments.

\section{References}

1. Hoy D, et al. The global burden of low back pain: estimates from the Global Burden of Disease 2010 study. Ann Rheum Dis , 2014.73 (6): 968-74.

2. Rubin DI. Epidemiology and risk factors for spine pain. Neurol Clin, 2007. 25 (2): 353-71.

3. Frymoyer JW, Cats-Baril WL. An overview of the incidences and costs of low back pain. Orthop Clin North Am, 1991. 22 (2): 263-71.

4. Oliveira CB, et al. Clinical practice guidelines for the management of non-specific low back pain in primary care: an updated overview.Eur Spine J , 2018. 27 (11): 2791-2803.

5. Popescu A, Lee H, Neck Pain and Lower Back Pain. Med Clin North Am, 2020. 104 (2): 279-292.

6. Urits I, et al. Low Back Pain, a Comprehensive Review: Pathophysiology, Diagnosis, and Treatment. Curr Pain Headache Rep , 2019. 23 (3): 23.

7. Vlaeyen JWS, et al. Low back pain. Nat Rev Dis Primers, 2018.4 (1): 52.

8. Huang M, Liao LR, Pang MY. Effects of whole body vibration on muscle spasticity for people with central nervous system disorders: a systematic review. Clin Rehabil , 2017. 31 (1): 23-33.

9. Ritzmann R, Stark C, Krause A. Vibration therapy in patients with cerebral palsy: a systematic review. Neuropsychiatr Dis Treat, 2018. 14 : 1607-1625.

10. Rüütel E, Vinkel I, Eelmäe P. The Effects of Short-Term Vibroacoustic Treatment on Spasticity and Perceived Health Conditions of Patients with Spinal Cord and Brain Injuries. Music 83 Medicine , 2017. 9 (3): 202-208.

11. Skille O. VibroAcoustic Therapy. Music Therapy, 1989.8 (1): 61-77.

12. Bartel L, Mosabbir A. Possible Mechanisms for the Effects of Sound Vibration on Human Health. Healthcare (Basel, Switzerland), 2021.9 (5): 597.

13. Campbell EA. Vibroacoustic Treatment and Self-care for Managing the Chronic Pain Experience: An Operational Model. JYU Dissertations, 2019. 95 .

14. Desmoulin GT, et al. Spinal Intervention Efficacy on Correcting Cervical Vertebral Axes of Rotation and the Resulting Improvements in Pain, Disability and Psychsocial Measures. Journal of Musculoskeletal Pain , 2012. 20 (1): 31-40.

15. Desmoulin GT, Yasin NI, Chen DW. Spinal mechanisms of pain control.Clin J Pain , 2007. 23 (7): $576-85$.

16. Kantor J, et al. Potential of Vibroacoustic Therapy in Persons with Cerebral Palsy: An Advanced Narrative Review. Int $j$ environ res and public health , 2019. 16 (20): 3940.

17. Desmoulin GT, Hewitt CR, Hunter CJ. Disc strain and resulting positive mRNA expression from application of a noninvasive treatment.Spine (Phila Pa 1976), 2011. 36 (14): E921-8. 
18. Desmoulin GT, Yasin NI, Chen DW. Initial Results Using Khan Kinetic Treatment as a Low Back Pain Treatment Option. Journal of Musculoskeletal Pain, 2007. 15 (3): 91-102.

19. Chan CW, Peng P. Failed back surgery syndrome. Pain Med, 2011.12 (4): 577-606.

20. Proietti L, et al. Complications in lumbar spine surgery: A retrospective analysis. Indian j ortho, 2013. 47 (4): 340-345.

21. Rigoard P, et al. Multicolumn spinal cord stimulation for predominant back pain in failed back surgery syndrome patients: a multicenter randomized controlled trial. Pain, 2019.160 (6): 1410-1420.

22. Chandler GS 3rd, et al. Dorsal column stimulation for lumbar spinal stenosis. Pain Physician, 2003. 6 (1): $113-8$.

23. Costantini A, Buchser E, Van Buyten JP. Spinal cord stimulation for the treatment of chronic pain in patients with lumbar spinal stenosis. Neuromodulation , 2010. 13 (4): 275-9; discussion 279-80.

Tables

Table 1 . Location and Number of Treatment Pulses

\begin{tabular}{|c|c|c|c|c|c|}
\hline & $\begin{array}{l}\text { Treatment } \\
\text { location and } \\
\text { \# of pulses }\end{array}$ & $\begin{array}{l}\text { Treatment } \\
\text { location and } \\
\text { \# of pulses }\end{array}$ & $\begin{array}{l}\text { Treatment } \\
\text { location and } \\
\text { \# of pulses }\end{array}$ & $\begin{array}{l}\text { Treatment } \\
\text { location and } \\
\text { \# of pulses }\end{array}$ & $\begin{array}{l}\text { Treatment } \\
\text { location and } \\
\text { \# of pulses }\end{array}$ \\
\hline $\mathrm{Tx} \#$ & Cervical & Sternum & Thoracic & Lumbar & Sacrum/Iliac \\
\hline 1 & Lft C1 80 & & & & \\
\hline 2 & Lft C1 80 & & & & \\
\hline 3 & Lft C1 80 & & & & \\
\hline 4 & Lft C1 80 & 60 & & & \\
\hline 5 & Lft C1 80 & Lft Sc 60 & & $\mathrm{~L}^{+} 60$ & \\
\hline 6 & $\mathrm{C} 180 \mathrm{C}^{+} 40$ & 60 & & & \\
\hline 7 & $\mathrm{C} 5^{+} 40$ & & & & $\mathrm{~S} 3^{+} 60$ \\
\hline 8 & $\mathrm{C} 5^{+} 40$ & $60 ;$ Rt Sc 60 & & & \\
\hline 9 & & 60 & $\mathrm{~T} 3^{+} 60$ & $\mathrm{~L}^{+} 60$ & \\
\hline 10 & & & $\begin{array}{l}\mathrm{T} 4^{+} 60 ; \mathrm{T}^{+} \\
60\end{array}$ & & $\begin{array}{l}\text { Rt PSIS 80; } \\
\text { PIIS } 80\end{array}$ \\
\hline 11 & & & Lft T4 60 & & $\begin{array}{l}\text { Rt S1 } 60 ; \text { Rt } \\
\text { PSIS } 80\end{array}$ \\
\hline 12 & & & $\begin{array}{l}\text { Lft T4 60; } \\
\text { T5 } 5^{+} 60\end{array}$ & & $\begin{array}{l}\mathrm{S}^{+} 60 ; \mathrm{Rt} \\
\text { PSIS } 80\end{array}$ \\
\hline Periodic & Periodic & Periodic & Periodic & Periodic & Periodic \\
\hline follow-up & follow-up & follow-up & follow-up & follow-up & follow-up \\
\hline treatments & treatments & treatments & treatments & treatments & treatments \\
\hline $\begin{array}{l}\text { beginning } 8 \\
\text { weeks }\end{array}$ & $\begin{array}{l}\text { beginning } 8 \\
\text { weeks }\end{array}$ & $\begin{array}{l}\text { beginning } 8 \\
\text { weeks }\end{array}$ & $\begin{array}{l}\text { beginning } 8 \\
\text { weeks }\end{array}$ & $\begin{array}{l}\text { beginning } 8 \\
\text { weeks }\end{array}$ & $\begin{array}{l}\text { beginning } 8 \\
\text { weeks }\end{array}$ \\
\hline following & following & following & following & following & following \\
\hline treatment 12 & treatment 12 & treatment 12 & treatment 12 & treatment 12 & treatment 12 \\
\hline 1 & Lft $\mathrm{C} 180$ & & $\mathrm{~T} 5^{+} 60$ & & $\begin{array}{l}\text { Rt S1 60, S5 } \\
60\end{array}$ \\
\hline 2 & Lft C1 80 & 60 & & $\mathrm{~L}^{+} 60$ & Rt PSIS 60 \\
\hline 3 & $\begin{array}{l}\text { Lft C1 } 80 \mathrm{C}^{+} \\
40 \mathrm{C} 7^{+} 40\end{array}$ & & & $\mathrm{~L}^{+} 60$ & Rt PSIS 80 \\
\hline 4 & Lft C1 80 & $\begin{array}{l}60 ; \text { Rt Sc } 60 \\
\text { Lft Sc } 60\end{array}$ & & $\mathrm{~L}^{+} 60$ & \\
\hline 5 & Lft C1 80 & $60 ;$ Rt Sc 60 & & $\mathrm{~L}^{+} 60$ & Rt PSIS 80 \\
\hline
\end{tabular}




\begin{tabular}{llllll}
\hline & $\begin{array}{l}\text { Treatment } \\
\text { location and } \\
\text { \# of pulses }\end{array}$ & $\begin{array}{l}\text { Treatment } \\
\text { location and } \\
\text { \# of pulses }\end{array}$ & $\begin{array}{l}\text { Treatment } \\
\text { location and } \\
\text { \# of pulses }\end{array}$ & $\begin{array}{l}\text { Treatment } \\
\text { location and } \\
\text { \# of pulses }\end{array}$ & $\begin{array}{l}\text { Treatment } \\
\text { location and } \\
\text { \# of pulses }\end{array}$ \\
\hline 6 & Lft C1 80 & $60 ;$ Rt Sc 60 & & & $\begin{array}{l}\mathrm{S} 1^{+} 60 ; \\
\text { Hypogastrium } \\
\end{array}$ \\
& & & & 60 \\
\hline
\end{tabular}

Lft=left; PIIS $=$ Posterior inferior iliac spine; PSIS $=$ Posterior superior iliac spine; Rt=right; $\mathrm{Sc}=$ sternoclavicular; $\mathrm{Tx}=$ Treatment.

${ }^{+}$Midline

\section{Figures}

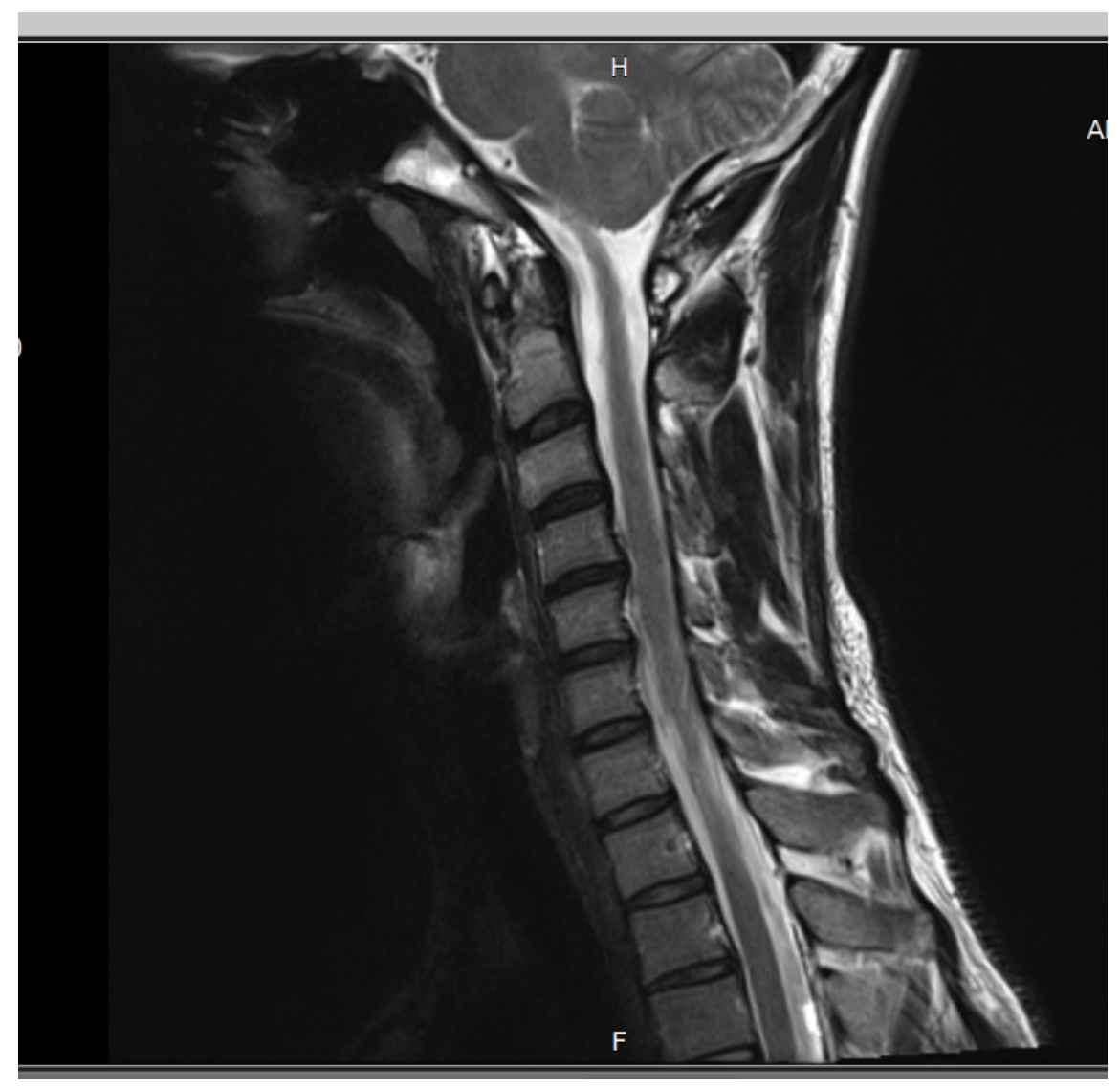

Figure 1. MRI of the cervical spine before treatment showing bulging of the disc between the $\mathrm{C} 3-\mathrm{C} 4$ and C4-C5 regions. 


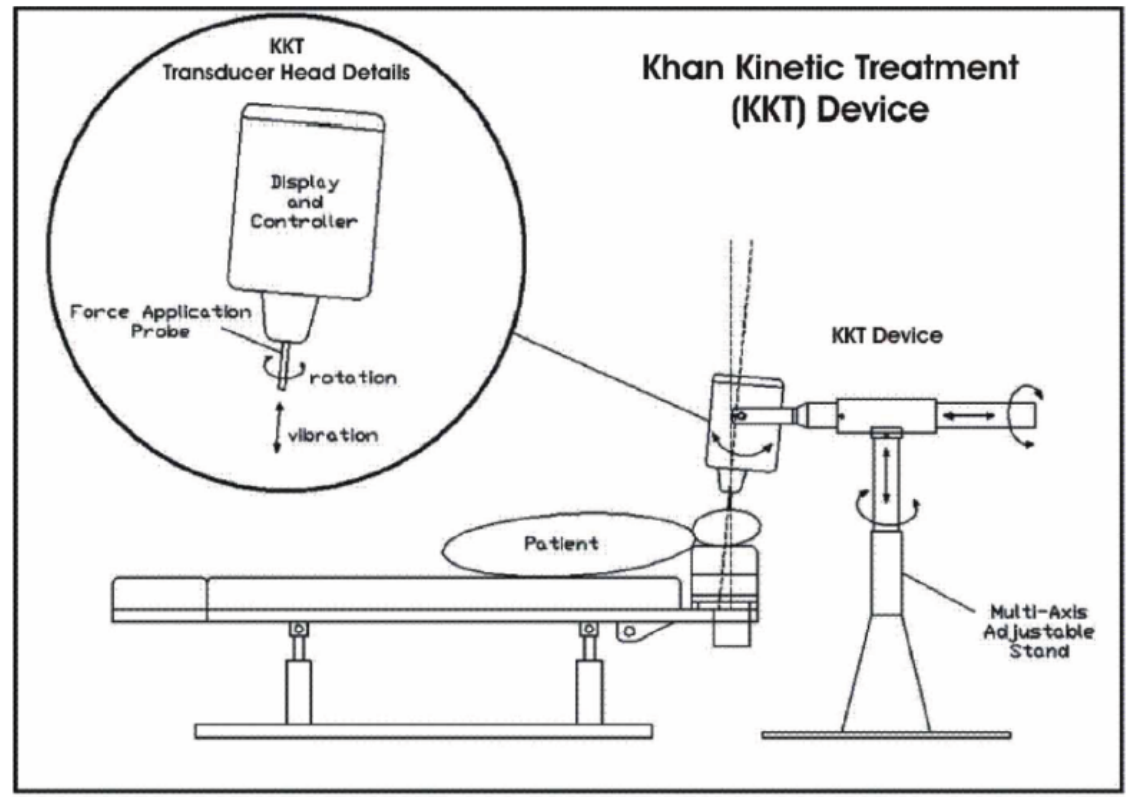

Figure 2. KKT device. 


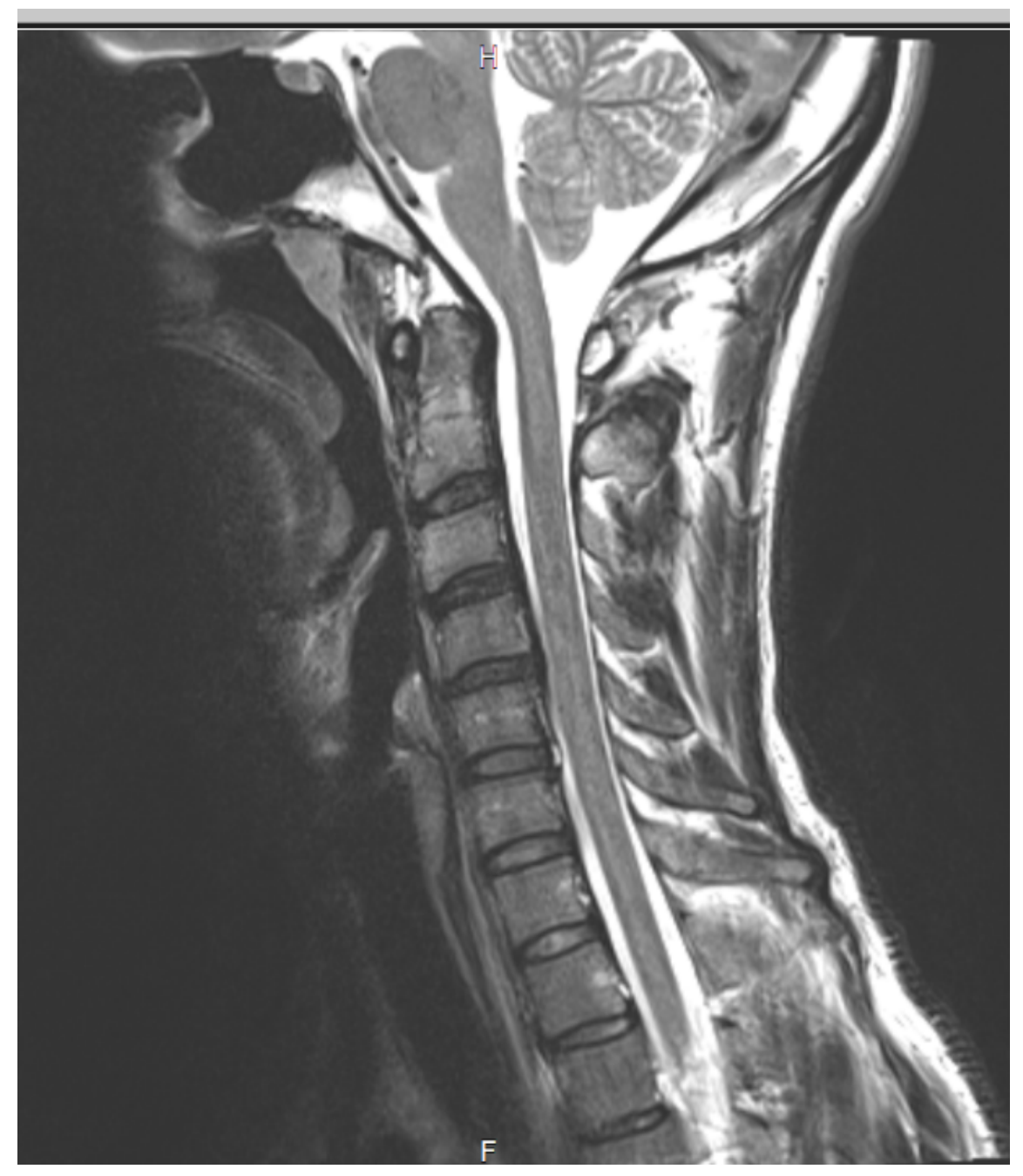

Figure 3. MRI of the cervical spine after treatment revealing no stenosis in the cervical spine 